Fundamentos da psicanálise de Freud a Lacan, vol. 2: A clínica da fantasia

Marco Antonio Coutinho Jorge Rio de Janeiro: Zahar, 2010, 288 págs.

\title{
A fantasia e sua travessia
}

\author{
Alessandro Melo Bacchini*1
}

No segundo volume dos Fundamentos da psicanálise de Freud a Lacan, Coutinho Jorge aborda a fantasia - definida em articulação à pulsão e ao inconsciente - de forma a situar o segmento da obra de Freud então intitulado "ciclo da fantasia", em que se verifica grande produtividade, reorganização e ressignificação de conceitos fundamentais. Com essa via de análise, tem-se a elevação da fantasia ao estatuto de um conceito, por seu caráter fundador e mediador do encontro do sujeito com o real.

Os conceitos fundamentais de inconsciente e a pulsão abrem caminho ao que Coutinho Jorge nomeia como o ciclo da fantasia, período fértil de produção freudiana que pode ser situado entre os anos 1906 e 1911, onde são destacadas as seguintes obras: "Delírios e sonhos na Gradiva de Jensen" (1907[1906]), "O poeta e o fantasiar" (1908[1907]), "Fantasias

*1 Pontifícia Universidade Católica do Rio de Janeiro - PUC-Rio (Rio de Janeiro, RJ, Br). 
histéricas e sua relação com a bissexualidade" (1908), "Sobre as teorias sexuais da criança" (1908), "Romances familiares" (1908), e "Formulações sobre os dois princípios do funcionamento mental" (1911).

Deve-se notar que a conclusão do ciclo da fantasia em um mesmo período de estudo voltado ao caso Schreber (1911) cumpre a fundamental função de apreender a estrutura do delírio como análoga à da fantasia no psiquismo, uma vez que ambos regulam, de forma diversa, a relação do sujeito com a realidade. O lugar da fantasia no aparelho psíquico tem por função primordial produzir uma satisfação que, se por um lado é negada na realidade, por outro continua a ser exigida pela pulsão - conciliação, portanto, de dois imperativos antagônicos: o do pulsional e o da realidade.

No segundo momento dos Fundamentos da psicanálise de Freud a Lacan, trabalham-se os conceitos de sintoma e fantasia, e articulam-se os temas do amor e do gozo. Para tanto, a criação do conceito de pulsão de morte e a releitura da função da fantasia apontam para uma maior compreensão da relação entre real e realidade, bem como as contenções exercidas pela fantasia ao real do gozo destrutivo da pulsão de morte. Fantasia — relacionada à neurose - e delírio - relacionado à psicose — constituem, assim, esforços simbólicos e imaginários diante do inassimilável do real, possibilitando a formação do laço social.

Os conceitos de pulsão e inconsciente são então aproximados, a partir de Lacan, com a leitura da estrutura do Real: elemento conceitual que categoriza o impossível de ser simbolizado. Este será o núcleo comum que se traduz em duas formas distintas: seja no campo da linguagem — do inconsciente - em que o real pode ser representado pelo $S(\mathbb{A})$, falta do significante da diferença sexual no inconsciente; seja no campo da sexualidade — pulsão — onde o real é nomeado como objeto $a$ - falta no imaginário do objeto do desejo. De outro modo, pode-se dizer que o inconsciente é um saber, mas um saber não todo que, da falta, somente reconstitui a dimensão de seu enigma.

Se para Lacan toda pulsão é pulsão de morte, ainda que aquela mostre sua face sedutora de pulsão sexual, ela deseja — em última instância — obter por meio do objeto sexual o objeto impossível — das Ding. De fato, valorizando a contribuição de Freud (1920) em "Mais além do princípio de prazer", em que a repetição é situada em dependência da pulsão de morte, tem-se um alcance clínico ampliado no que diz respeito ao sintoma: este é o que se repete na transferência. Nesse sentido, a análise opera a travessia do sintoma à fantasia a ele subjacente, desembocando no real que sustenta a estrutura psíquica não toda estruturada como uma linguagem pelo simbólico. 
Todo este percurso ocorre na neurose onde há a ação do Nome-do-Pai na operação do recalque originário. Como resultante, a instauração da fantasia fundamental como matriz do inconsciente constitui uma forma fixa e repetitiva do sujeito se relacionar com a causa do desejo. Já na psicose, ocorre algo diverso, pois a foraclusão do significante Nome-do-Pai resulta numa falha do recalque originário. Com essa falha, a fantasia não é instaurada e o psicótico tenderá a produzir um delírio para preencher essa lacuna.

Para estabelecer diferenciações entre neurose e perversão, Coutinho Jorge utiliza-se do matema da fantasia: $\$<$ a. A partir deste, pode-se verificar dois polos: de um lado o $\$$, o polo inconsciente, o sujeito constituído pela linguagem e por ela mesma barrado em sua completude; de outro, o polo pulsional, com o elemento que se inscreve na fantasia como o mais-gozar.

Com essa construção, Coutinho Jorge postula que, em última instância, a fantasia é sempre de desejo de completude, constituída em torno de dois polos diferenciados: amor e gozo.

Tal noção de gozo é apreendida do sentido lacaniano como algo para sempre perdido - perda inscrita justamente quando houve a entrada do sujeito no mundo simbólico. Disso, depreende-se a oposição entre saber 344 e gozo, pois onde o simbólico inscreve o sujeito falante não há mais gozo. Nesse sentido, a neurose é um não querer saber operado pelo recalque, é um gozar no sintoma. Sobre a fantasia, esta seria uma tentativa de preencher o gozo perdido, construindo-se essencialmente como fantasia de completude.

Chegando à terceira e última parte de seu trabalho, Coutinho versa acerca da travessia em que se dá o despertar para o não sentido do real. Esse sentido é empregado em seu ensino com referência ao terceiro momento das contribuições teóricas de Lacan, em que a travessia da análise implica um mais-além da travessia da fantasia em seus sentidos voltados para o simbólico e o real. Para tanto, Coutinho Jorge lança mão da análise estética e literária, bem como de sua admirável experiência clínica, o que revigora o desenvolvimento teórico da experiência do despertar. Além disso, chama atenção a leitura magistral de Clarice Lispector, tomada por Coutinho Jorge como exemplar de uma sensibilidade que toca tão profundamente a alma humana em sua radicalidade.

Citação/Citation: Bacchini, A.M. (2016, junho). A fantasia e sua travessia. Resenha do livro Fundamentos da psican[alise de Freud a Lacan. Vol. 2: A clínica da fantasia, de Marco Antonio Coutinho Jorge. Revista Latinoamericana de Psicopatologia Fundamental, 19(2), $342-345$. 


\section{RESENHAS BIBLIOGRÁFICAS}

Editor do artigo/Editor: Profa. Dra. Sonia Leite

Recebido/Received: 26.9.2015/ 9.26.2015 Aceito/Accepted: 30.10.2015 / 10.30.2015

Copyright: (C) 2009 Associação Universitária de Pesquisa em Psicopatologia Fundamental/ University Association for Research in Fundamental Psychopathology. Este é um artigo de livre acesso, que permite uso irrestrito, distribuição e reprodução em qualquer meio, desde que o autor e a fonte sejam citados / This is an open-access article, which permits unrestricted use, distribution, and reproduction in any medium, provided the original authors and sources are credited.

\section{Alessandro Melo Bacchini}

Doutorando em Psicologia Clínica pela Pontifícia Universidade Católica do Rio de Janeiro - PUC-Rio (Rio de Janeiro, RJ. Br); Mestre em Psicologia Clínica e Social pela Universidade Federal do Pará - UFPA (Belém, PA, Br); Membro do Laboratório de Psicanálise e Psicopatologia Fundamental (LPPF - Belém/PA) e pesquisador Associado do Laboratório Interdisciplinar de Pesquisa e Intervenção Social - LIPIS/PUC-Rio.

Rua Riachuelo, 257/421 - Centro 22023-011 Rio de Janeiro, RJ, Br. alessandromelobacchini@gmail.com

This is an open-access article, which permits unrestricted use, distribution, and reproduction in any medium for non-commercial purposes provided the original authors and sources are credited. 